Utah State University

DigitalCommons@USU

Extension Research

Extension

10-19-2018

\title{
Health Effects of Late-Career Unemployment
}

\author{
Maren Wright Voss \\ Utah State University, Maren.Voss@usu.edu \\ Lori L. Wadsworth \\ Brigham Young University \\ Wendy Birmingham \\ Brigham Young University \\ M. Beth Merryman \\ Towson University \\ Lisa Crabtree \\ Towson University \\ Kathy Subasic \\ Towson University
}

See next page for additional authors

Follow this and additional works at: https://digitalcommons.usu.edu/extension_research

Part of the Medicine and Health Sciences Commons

\section{Recommended Citation}

Voss, Maren Wright, et al. "Health Effects of Late-Career Unemployment." Journal of Aging and Health, Oct. 2018, doi:10.1177/0898264318806792.

This Article is brought to you for free and open access by the Extension at DigitalCommons@USU. It has been accepted for inclusion in Extension Research by an authorized administrator of DigitalCommons@USU. For more information, please contact digitalcommons@usu.edu.

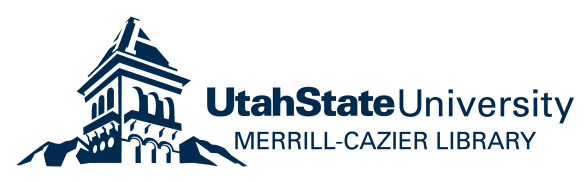




\section{Authors}

Maren Wright Voss, Lori L. Wadsworth, Wendy Birmingham, M. Beth Merryman, Lisa Crabtree, Kathy Subasic, and Man Hung 
Health Effects of Late-Career Unemployment

Maren Wright Voss, $\mathrm{ScD}^{1,4}$; Lori L. Wadsworth, $\mathrm{PhD}^{2}$; Wendy Birmingham, $\mathrm{PhD}^{3}$; M. Beth Merryman, $\mathrm{PhD}^{4}$; Lisa Crabtree, $\mathrm{PhD}^{4}$; Kathy Subasic, $\mathrm{PhD}^{4}$; Man Hung, $\mathrm{PhD}^{1}$

${ }^{1}$ University of Utah Department of Orthopaedics ${ }^{2}$ Brigham Young University Romney Institute of Public Management ${ }^{3}$ Brigham Young University Department of Psychology

${ }^{4}$ Towson University Department of Occupational Therapy and Occupational Science

Maren Wright Voss, ScD: Corresponding author

Utah State University Cooperative Extension

Email: maren.voss@usu.edu

Phone: 240-367-4777 


\begin{abstract}
Job loss has a demonstrated negative impact on physical and mental health. Involuntary retirement has also been linked to poorer physical and mental health outcomes. This study examined whether late-career unemployment is related to involuntary retirement and health declines post-retirement. Analysis was conducted using the 2000-2012 U.S. Health and Retirement Study (HRS) survey data with unemployment months regressed with demographic and baseline health measures on physical and mental health. Individuals with late-career unemployment reported more involuntary retirement timing (47.0\%) compared to those reporting no unemployment $(27.9 \%)$. Late-career unemployment had no significant effect on self-reported physical health $(\beta=.003, p=0.84)$, but was significantly associated with lower levels of mental health $(ß=.039 ; p<.01)$. Self-reports of late-career unemployment are not associated with physical health in retirement, but unemployment is associated with involuntary retirement timing and mental health declines in retirement. Unemployment late in the working career should be addressed as a public mental health concern.
\end{abstract}

Key Words: Retirement Timing; Unemployment; Adaptation; Health and Retirement Study 


\section{Health Effects of Late-Career Unemployment}

\section{Introduction}

The US population is aging overall, from nearly 48 million persons over age 65 in the US in 2015 to an expected 82 million by 2040 (Aging, 2017). At the same time, the labor force is aging with a trend toward delayed retirement since the 1990's that has accelerated since the 2008 recession (Levanon \& Cheng, 2011). In fact, the percentage of individuals expecting to work past the age of 65 has increased from $11 \%$ in 1992 to $42 \%$ by 2010 (Quinn, 2010). It is important to understand the health impact of retirement timing and work opportunity among older adults, particularly as the costs of caring for an aging population burden the public health system. The current study tests the hypothesis that there is a relationship between late-career job loss and retirement age and health outcomes (physical and mental) in a U.S. population of mature adults.

\section{Retirement Health Effects}

It is clear that overall physical health and life satisfaction decline in the years following formal retirement at the population level (Behncke, 2012; Moon, Glymour, Subramanian, Avendano, \& Kawachi, 2012), to the point that early retirement has been considered a risk factor for mortality (Wu, Odden, Fisher, \& Stawski, 2016). Yet meta-analysis incorporating complex mediators and moderators presents a more nuanced picture of retirement health, yielding inconclusive evidence on whether retirement results in improved or declining health (van der Heide, van Rijn, Robroek, Burdorf, \& Proper, 2013). Retirement is an increasingly complex and dynamic construct as the population ages and retirement periods lengthen (Furunes et al., 2015; Wang \& Shultz, 2010). The inconclusive evidence about the health effects of retirement is likely 
the result of the many complicated factors surrounding the reasons and conditions behind retirement decisions.

A number of studies have found that a planned, voluntary, and pensioned early retirement results in improved physical health levels (Bloemen, Hochguertel, \& Zweerink, 2017; Coe \& Zamarro, 2011; Eibich, 2015; Jokela et al., 2010), with improvements in health typically ascribed to better health behaviors. Yet this first group of retirees (early, planned, and voluntary) are apparently not the typical retirement story, as decades of population level data show physical health deteriorates after retirement (Behncke, 2012; Ekerdt, Bosse, \& LoCastro, 1983; Kachan et al., 2015; Kremer, 1985; Moon et al., 2012; Zhan, Wang, Liu, \& Shultz, 2009). In a second group of retirees, those forced to work longer than expected (involuntary, delayed retirement) physical health tends to decline on average (Shai, 2017). In a third group, unable to find extended work opportunities after formal retirement (involuntary, full-time retirement) the endresult is declines in life satisfaction (Dingemans \& Henkens, 2014) which have been linked to negative health impacts including risk of dementia (Peitsch, Tyas, Menec, \& St John, 2016) and time to death (Gerstorf, Ram, Röcke, Lindenberger, \& Smith, 2008). These conflicting findings about the health effects of retirement point towards the context surrounding retirement decisions as important elements in understanding health effects.

Voluntary/Involuntary Retirement

Voluntary retirement can be measured with a self-report item that asks retired individuals to recall the amount of choice they had at the time of their retirement. It can also be calculated indirectly, as the difference between planned and actual retirement age. While studies use different ways of measuring retirement voluntariness, it appears that whether or not retirement was a voluntary choice is key to understanding the complex processes and impacts of retirement 
(Beehr, 1986). Some studies suggest that only involuntary retirees show declining physical health (Dave, Rashad, \& Spasojevic, 2008; Rhee, Mor Barak, \& Gallo, 2016; Van Solinge, 2007) and only voluntary retirees show significant increases in happiness levels following retirement (Calvo, Haverstick, \& Sass, 2009). A number of factors influence whether or not individuals feel they have choice in their retirement decisions. Economic evidence indicates that job stability prior to retirement has a large impact on the voluntariness of retirement timing. Economic recessions and higher unemployment rates that occur in the years just before an individual's retirement age both increase early retirement rates (Chan \& Stevens, 2004), as well as show a negative impact on individual level physical health (Burgard, Ailshire, \& Kalousova, 2013) and cognitive function (Leist, Hessel, \& Avendano, 2014). So in addition to the three groups of retirees mentioned above, there may be a fourth group in which the early and unplanned retirement is not necessarily considered involuntary, but yet retirement was precipitated by a loss of work opportunity and a loss of choice.

Health Effects of Lost Work Opportunity

In this work we explore a potential link between the health impacts of early, unplanned retirement and the well-researched negative health impacts of unemployment. Unemployment shares with retirement the change from working to non-working status, but with unemployment there is a clear lack of choice which results in lost work opportunity. Unemployment results in higher mortality (Browning \& Heinesen, 2012; Granados, House, Ionides, Burgard, \& Schoeni, 2014; Jin, Shah, \& Svoboda, 1995; Sullivan \& Von Wachter, 2009) and is associated with unhealthy lifestyle factors (Browning \& Heinesen, 2012; Rosenthal, Carroll-Scott, Earnshaw, Santilli, \& Ickovics, 2012) and declining mental health (Dooley, Fielding, \& Levi, 1996; Flint, Bartley, Shelton, \& Sacker, 2013; Paul \& Moser, 2009). 
The study of unemployment health effects shares a methodological concern with studying retirement health, given the concern that there is a confounding effect when those who are already sick or disadvantaged in health are then more likely to lose their jobs or retire early due to health concerns (Bockerman \& Ilmakunnas, 2009; Salm, 2009; Schmitz, 2011). Yet the majority of the studies cited have controlled for health mediators such as socioeconomic and prior health status and still point to involuntary job loss as an independent predictor of negative health outcomes. Researchers have identified biological markers such as C-reactive protein, an indicator of inflammatory response, in the unemployed (Hughes, Kumari, McMunn, \& Bartley, 2017) as well as higher odds of metabolic syndrome following unemployment (Varanka-Ruuska et al., 2017). The underlying mechanisms related to the health impacts of lost work opportunity are still being explored.

There a differing opinions on the theoretical underpinnings of how lost work opportunity results in negative health outcomes. One theory suggests that job loss is related to fiscal disadvantage, and that loss of income is the driving force behind the negative health effects (Fryer, 1986). Another widely held theory is the latent deprivation model, which states that lost work opportunity causes five areas of latent deprivation, through changes in rhythms of time use, reduced social connections, loss of participation in collective purposes, loss of social status, and loss of personal identity (Jahoda, 1982). The proposed potential mechanisms for the health effects of job loss span across the bio-psycho-social model of health. While the underlying mechanisms are important, in order to address whether lost work opportunity is related to retirement health, we must first answer the question of whether or not job loss is related to changes in health following the retirement transition.

Lost Work Opportunity among Mature Adults 
The evidence that unemployment has a negative health effect are potentially more impactful to the health of older individuals. A $1 \%$ increase in unemployment rates at age 58 yields a 10\% increase in death rates by age 79 (Coile, Levine, \& McKnight, 2014). In addition, older adults are more susceptible to extended unemployment, with workers over age 55 averaging 43 weeks of unemployment compared to just 32 weeks for younger workers in the US in 2010 (Van Horn, Corre, \& Heidkamp, 2011). There is overlap between unemployment and retirement among older unemployed workers. Older workers are more likely to leave the workforce when unemployment strikes at rates of 3 to 1 , compared to workers under the age of 55 (Coile \& Levine, 2011). When unemployment benefits run out, retirement rates rise, particularly for pension or social security eligible workers aged 62-69 (Coile \& Levine, 2011). The reasons behind how and why older adults exit the workforce are complex (G. G. Fisher, Chaffee, \& Sonnega, 2016) and may hold the key to understanding why there are differential health effects in retirement depending on whether retirement is voluntary or involuntary. Measurement Issues of Lost Work Opportunity

The evidence presented thus far points to two clear outcomes: a negative physical and mental health effect of unemployment and an increased tendency to retire when unemployment strikes late in a working career. This evidence points to how a fourth group of retirees with unplanned retirement may have un-examined health effects. This group of retirees facing a loss of work opportunity may feel forced into an early, unplanned retirement without ever reporting their status as unemployed or their retirement as involuntary. Whether or not this early retirement is labeled as voluntary or involuntary is an open question, but the increased rates of early retirement during economic recessions suggests an association between unemployment and involuntary early retirement (Coile \& Levine, 2011). When job loss is the reason behind an early 
and involuntary retirement selection, mental health declines, but evidence suggests that workforce re-entry restores mental health to prior levels (Mandal \& Roe, 2008) and improves life satisfaction (Dingemans \& Henkens, 2014). If a return to work is impactful for this fourth group of retirees, it becomes important to identify and understand how lost work opportunity has impacted health.

Yet measuring involuntary retirement is not an easy proposition. Early departures from the work-force may be labeled as retirement choices rather than as disability claims or unemployment claims (Chan \& Stevens, 2004). This may be because retirement as a labor force status has a more positive connotation and carries less social stigma than the status of unemployment (Hetschko, Knabe, \& Schöb, 2014). Older workers face difficult job-search obstacles such as updating skills for a changing job market, age discrimination, and reemployment options that do no match their prior income levels (Chan \& Stevens, 2004), making re-employment less attractive. Yet if there is a health advantage to working to full retirement age, as some evidence suggests (Wu et al., 2016), it would be important to remove the obstacles to workforce re-entry for older adults. Identifying when retirement has occurred due to job loss, rather than retirement planning, is an important consideration in understanding the health effects of retirement. The current study tests the hypothesis that there is a relationship between latecareer job loss and retirement age and health outcomes (physical and mental) in a U.S. population of mature adults.

\section{Methods}

This quantitative analysis utilized the Health and Retirement Study (HRS), which is conducted and administered by the National Institutes of Health, Institute on Aging. The HRS is 
a longitudinal health survey conducted every two years in the United States on a cohort of adults aged 50 years and older and their spouses (Chien et al., 2015). It is a survey designed to study the health of older adults as they navigate the transitions through late adulthood. The survey includes detailed information on both labor force status and health status, which is assessed in a number of ways including number of chronic conditions, prescription medications, body mass index, and other physical and mental health measures.

Population/recruitment. Individuals included in the initial cohort of the HRS longitudinal health survey were born between 1931 and 1941, and supplemental cohorts have been added in periodic waves. In 1992 a screening of 69,337 households with a response rate of 99.6\% yielded an initial eligible sample of 15,497 individuals for interviewing. From this initial group, 12,652 surveys were obtained, yielding a total response rate of $81.6 \%$. By 2008 , additional cohorts had been added and the sample was expanded to 31,000 participants (RAND, 2000-2012). By 2008 1,763 study participants (5.7\%) had requested to be permanently removed from the survey collection process. Data from the HRS are publicly available at (http://hrsonline.isr.umich.edu/). The RAND Corporation has produced user-friendly longitudinal compilations of the individual waves of the HRS dataset. The RAND HRS (Version P) was utilized in this analysis, a cleaned and processed longitudinal file made publicly available by the RAND Corporation (Chien et al., 2015).

Measures. The HRS survey identifies labor force status with the question, "Now I'm going to ask you some questions about your current employment situation. Are you working now, temporarily laid off, unemployed and looking for work, disabled and unable to work, retired, a homemaker, or what?" Retirement coding is checked against reported hours working for pay so that a working individual, whether working part-time or full-time, is not coded as 
retired (Chien et al., 2015). Outcome measures for health and well-being are important considerations, as researchers have identified different health effects depending on the type of health outcome being analyzed (Browning \& Heinesen, 2012; Browning, Moller Dano, \& Heinesen, 2006). Three measures of physical health from the 2012 survey were included as outcome variables in this analysis, addressing subjective and objective health assessment. These include self-reported physical health, number of chronic conditions, and number of nights spent in the hospital in the last year.

Self-reported physical health was answered by a single question, 'Would you say your health is excellent, very good, good, fair, or poor?' Because the data are longitudinal, death in a subsequent year results in missing data for self-reported health and hospital records in subsequent surveys. To address this limitation, death records were combined and included into a constructed variable for self-rated health. Self-rated health was reverse coded so that poor health $=1$ and excellent health $=5$, and morbidity information was coded as a value of 0 to construct an improved measure of self-reported health. Number of chronic conditions was calculated as the sum of self-reported conditions for which the respondent had ever had a doctor inform them of having a diagnosis. There are eight chronic conditions queried including high blood pressure, diabetes, cancer, lung disease, heart disease, stroke, psychiatric problems, and arthritis. The number of chronic conditions was taken from the 2012 survey wave and calculated as a sum of self-reported doctor diagnosed conditions. Number of nights spent in the hospital within the past year, as recorded in the 2012 survey data, was included as a third measure of physical health status.

Depression scores were included as a covariate to control for prior mental health utilizing the Center for Epidemiological Studies-Depression (CES-D) measure (Radloff, 1977). The scale 
includes nine questions assessing sleep, mood, and energy levels. Administration of this scale in the HRS differed from the standardized version of the CES-D as respondents were asked to answer 'yes' or 'no' to the questions rather than answering on the 5-point scale in the standard administration. For example, respondents were asked, 'Now think about the past week and the feelings you have experienced. Please tell me if each of the following was true for you much of the time during the past week.' This prompt was followed by nine yes or no queries including; 1) felt depressed, 2) felt that everything you did was an effort, 3) your sleep was restless, 4) you were happy, 5) you felt lonely, 6) you enjoyed life, 7) you felt sad, 8) you could not get going, and 9) you had a lot of energy. Total scores ranged from zero (no depressive symptoms) to nine (severe depressive symptoms), with items four and six reverse-coded. The CES-D has demonstrated adequate internal consistency (Cronbach's alpha $=.80-.90)$ and reliability $(\mathrm{r}=.41$ .70) (Gonzalez et al., 2017; Radloff, 1977). The CES-D total score was tallied and computed as a single variable by the RAND Corporation.

Number of months unemployment was the primary predictor variable. The HRS in each survey wave asks respondents who report their labor status as unemployed to identify the month and year the unemployment began. For each respondent, total months of unemployment was calculated. To calculate this variable, the first month of unemployment was subtracted from the month of the survey. This created a count of the total number of months of unemployment at the time of the survey date. The number of months of unemployment extending past the survey date were not captured in the data unless that unemployment episode extended longer than 2 years and lasted until the following survey collection time-point. Number of months of unemployment were added across survey waves and were coded at a maximum of 60 months or 5 years of 
unemployment to differentiate unemployment from long-term disability or other reasons for remaining outside of the labor force.

Covariates were identified through literature review and included age, gender, race, income, region, and education level (Chen, Rizzo, \& Rodriguez, 2011). Age and income were included as continuous variables. Gender, race, region, and education were included as categorical variables. Region was based on census regions and was included to adjust for the influence of regional variations that exist in health spending and outcomes (E. S. Fisher et al., 2003). Education was divided into four categories of less than high school, high school graduate or GED, some college through four-year degree, or some graduate school and beyond. Regular engagement in vigorous, moderate, and/or light activities was tested in the model as a covariate to account for differing activity levels among seniors, but did not alter the outcomes and was not included in the final model.

Data analysis. The sample was selected for all individuals aged 50 or older in the 2000 survey data who were coded as still in the labor force (not retired or disabled). Having follow-up in year 2012 allowed for 12 years of data collection on unemployment and a range of timeintervals between unemployment and retirement. Health outcomes measurement was drawn from the 2012 survey wave, as the goal of the research was to look beyond short-term effects and determine if there are broad and lasting physical and mental health effects of late-career unemployment on retirement health.

Descriptive analysis was performed for the final sample meeting inclusion criteria and statistics reported as means and standard deviations for all continuous variables, and as percentages for categorical variables. Ordinal data drawn from Likert scale survey questions 
were analyzed with parametric statistics (Norman, 2010). Assumptions of multivariate normality, linearity, multicollinearity, and homoscedasticity were tested.

Multivariate regression analysis was conducted with the demographic variables as covariates and late-career unemployment as the independent variable. Demographic and individual variables included prior health status, prior CES-D, age, gender, race/ethnicity, financial resources, education level, marital status, and census region. The dependent variables assessed included self-reported physical health status, number of chronic conditions, number of nights spent hospitalized, and mental health status measured by the CES-D. Self-reported health has been found to be a reliable indicator of health outcomes (Cheak-Zamora, Wyrwich, \& McBride, 2009; Salyers, Bosworth, Swanson, Lamb-Pagone, \& Osher, 2000). However, research on the health effects of unemployment have shown that the manner in which health is measured can alter the conclusions that are drawn (Browning \& Heinesen, 2012; Browning et al., 2006), thus objective and subjective reports of health were included to address consistency of the outcomes assessed. Variables were weighted with the population weights provided by the HRS survey and were scaled to reflect the U.S. population demographics for the Current Population Survey in March of each survey year (http://hrsonline.isr.umich.edu/sitedocs/wghtdoc.pdf). All analyses were conducted using STATA SE 14.0 (StataCorp, 2015).

\section{Results}

A total of 11,762 respondents were surveyed in the 2000 wave of HRS data collection. Inclusion criteria were an age of 50 or older in 2000, being listed as in the labor force (not disabled or retired) in 2000 , and having provided responses to self-reported physical health and CES-D scores in the 2000 survey wave. The 2000 survey wave was used as the baseline sample to provide baseline health measures and to identify individuals age 50 and older who were active 
in the labor force in that year. Individuals who had retired in the next wave of 2002 and for the following 10 years (2002-2012 inclusive) were included in the final analysis. The final sample size included 8,099 individuals who participated in the labor force in 2000 and also provided self-reported physical health (or were listed in death records) and CES-D scores in the 2012 survey wave.

Analyses included descriptive statistics reported as means and standard deviations for all continuous variables, and as percentages for categorical variables (see Table 1). For the final sample of 8,099 individuals reporting prior health in 2000 and self-reported health or records of morbidity in 2012, the average age was $79.14(S D=7.25)$ and $63.5 \%$ of the sample was female. There were 529 individuals $(6.5 \%)$ who had experienced late-career unemployment after the age of 50, with an average combined length of unemployment of 17.5 months over the 12 years $(S D=15.76)$. The average retirement age for those experiencing late-career unemployment was $65.06(S D=6.03)$ while the average retirement age for those with stable late-career employment was age $63.66(S D=6.55)$. A total of $47.0 \%$ of those experiencing late-career unemployment reported involuntary retirement timing and 3.5\% felt partially forced into retirement. For those with no late-career unemployment, the involuntary retirement rate was $27.9 \%$ with an additional $2.8 \%$ as partially forced into retirement.

Table 1: Demographic information

\begin{tabular}{llccc} 
Variable & & $\mathbf{N}(\%)$ & Mean (SD) & Range \\
\hline Age & & $8099(100 \%)$ & $79.14(7.25)$ & $50-99$ \\
Race & Black/African & $1068(13.2 \%)$ & & \\
& American & & & \\
& White/Caucasian & $6730(83.1 \%)$ & & \\
Ethnicity & Other & $301(3.7 \%)$ & & \\
Gender & Hispanic & $653(8.1 \%)$ & & \\
& Male & $2953(36.5 \%)$ & &
\end{tabular}




\begin{tabular}{|c|c|c|c|c|}
\hline \multicolumn{2}{|l|}{ Variable } & \multirow{2}{*}{$\frac{N(\%)}{5146(625 \%)}$} & \multirow[t]{2}{*}{ Mean (SD) } & \multirow[t]{2}{*}{ Range } \\
\hline & Female & & & \\
\hline Marital Status & Married & $4277(52.2 \%)$ & & \\
\hline & Partnered & $181(2.2 \%)$ & & \\
\hline & Divorced & $737(9.1 \%)$ & & \\
\hline & Widowed & $2557(31.6 \%)$ & & \\
\hline & Never Married & $231(2.9 \%)$ & & \\
\hline & Other & $166(2.0 \%)$ & & \\
\hline Education & Less than HS & $1550(19.1 \%)$ & & \\
\hline & HS or GED & $2985(36.9 \%)$ & & \\
\hline & Some College & $1769(21.8 \%)$ & & \\
\hline & College Graduate & $1795(22.2 \%)$ & & \\
\hline Income & & $8099(100 \%)$ & $\begin{array}{c}\$ 58,973 \\
(\$ 99,829)\end{array}$ & $\begin{array}{c}\$ 0- \\
\$ 4,040,971\end{array}$ \\
\hline Unemployment & Unemployment & $529(6.5 \%)$ & $17.5(15.76)$ & $1-60$ \\
\hline Months & No unemployment & $7570(93.5 \%)$ & 0 & \\
\hline Age of & Unemployment & $529(6.5 \%)$ & $65.06(6.03)$ & \\
\hline Retirement & No unemployment & $7570(93.5 \%)$ & $63.66(6.55)$ & \\
\hline Involuntary & Unemployment & $249(47.0 \%)$ & & \\
\hline Retirement & No unemployment & $2112(27.9 \%)$ & & \\
\hline
\end{tabular}

Each variable with missing data over 3\% of the sample was analyzed for the dispersion of the data. Using the MCAR test in STATA the variables with missing data were identified as missing at random, and as such no multiple imputations of missing data were conducted. There was a lack of multi-collinearity between variables (correlations ranging from $\mathrm{r}=-0.002$ to -0.504 and VIF ranging from 1.02-2.27). Data for each variable were sufficiently normally distributed, though income data did present minimal outliers. There was no violation of the normality of the error terms analyzed both with q-q plots and Shapiro-Wilk's test for normality (W=0.99, $p<0.001$ ), completed with STATA statistical software. In the regression analysis age, income, and health outcomes were treated as continuous variables and gender, race, ethnicity, education, region, and marital status were treated as categorical variables.

Late-career unemployment had no significant effect on self-reported physical health ( $\beta=.003, p=0.84, \mathrm{~N}=8.099$ ) (see Table 2 ). Including involuntary retirement as a covariate did not alter the outcome, where late-career unemployment still showed no effect on self-reported 
physical health $(\beta=-.005, p=0.19, \mathrm{~N}=702)$ (results available upon request). Regression models run for objective measures of health outcomes (number of chronic conditions and the number of nights spent in the hospital over the past twelve months) also showed no significant effect of late-career unemployment on self-reported physical health (results available upon request). Latecareer unemployment was significantly associated with lower levels of mental health as measured by CES-D scores $(\beta=.039 ; p<.01, \mathrm{~N}=7,719)$ (see Table 3$)$.

Table 2: Factors associated with self-reported health

Estimated Regression Coefficients

\begin{tabular}{|c|c|c|c|c|c|}
\hline Univariate Model & b & $\boldsymbol{\beta}$ & $\begin{array}{c}\text { Standard } \\
\text { Error }\end{array}$ & t-Value & $\operatorname{Pr}>|\mathbf{t}|$ \\
\hline Intercept & 3.120 & & 0.013 & 248.10 & $<0.001$ \\
\hline Unemployment months & 0.002 & 0.012 & 0.002 & 0.98 & 0.329 \\
\hline Multivariate Model & $\mathbf{b}$ & $\boldsymbol{\beta}$ & $\begin{array}{c}\text { Standard } \\
\text { Error }\end{array}$ & t-Value & $\operatorname{Pr}>|t|$ \\
\hline Intercept & -11.393 & & 3.613 & -3.15 & 0.002 \\
\hline Unemployment months & 0.001 & 0.003 & 0.002 & 0.21 & 0.836 \\
\hline $\begin{array}{l}\text { Self-report Physical Health } \\
2000\end{array}$ & -0.435 & -0.436 & 0.013 & -32.75 & $<0.001$ \\
\hline CESD score 2000 & -0.038 & -0.066 & 0.007 & -5.15 & $<.0001$ \\
\hline Age in 2012 & 0.008 & 0.059 & 0.002 & 4.27 & $<0.001$ \\
\hline Gender (Male) & 0.000 & & 0.000 & . & . \\
\hline Female & 0.052 & 0.025 & 0.025 & 2.05 & 0.040 \\
\hline Race (White/Caucasian) & 0.000 & & 0.000 & & • \\
\hline Black/African American & -0.103 & -0.027 & 0.036 & -2.81 & 0.005 \\
\hline Other & -0.077 & -0.014 & 0.070 & -1.10 & 0.272 \\
\hline Ethnicity (Non-Hispanic) & 0.000 & & 0.000 & & \\
\hline Hispanic & 0.001 & 0.002 & 0.050 & 0.20 & 0.843 \\
\hline Household Income & 0.000 & 0.05 & 0.000 & 4.78 & $<0.001$ \\
\hline Education (Less than HS) & 0.000 & & 0.000 & & \\
\hline GED or HS & 0.085 & 0.040 & 0.037 & 2.29 & 0.022 \\
\hline No Degree, Some College & 0.152 & 0.062 & 0.040 & 3.79 & $<0.001$ \\
\hline College Graduate and above & 0.236 & 0.100 & 0.042 & 5.60 & $<0.001$ \\
\hline Marital Status (Married) & 0.000 & & 0.000 & & \\
\hline Partnered & -0.514 & -0.001 & 0.080 & -0.64 & 0.521 \\
\hline Divorced & -0.036 & -0.011 & 0.039 & -0.92 & 0.356 \\
\hline
\end{tabular}


Estimated Regression Coefficients

Widowed

Univariate Model

Never Married

Census Region (East)

Midwest

South

West

\begin{tabular}{cccrr} 
b & $\boldsymbol{\beta}$ & $\begin{array}{c}\text { Standard } \\
\text { Error }\end{array}$ & t-Value & \multicolumn{1}{c}{$\boldsymbol{P r}>|\mathbf{t}|$} \\
\hline 0.029 & -0.012 & 0.030 & -0.97 & 0.332 \\
0.035 & 0.001 & 0.073 & 0.48 & 0.629 \\
0.000 & & 0.000 & & \\
0.004 & 0.002 & 0.037 & 0.11 & 0.911 \\
0.030 & -0.014 & 0.034 & -0.88 & 0.379 \\
0.022 & 0.008 & 0.041 & 0.52 & 0.602
\end{tabular}

Table 3: Factors associated with mental health

Estimated Regression Coefficients

\begin{tabular}{lccccr}
\multicolumn{1}{c}{ Univariate Model } & b & $\boldsymbol{\beta}$ & Error & t-Value & Pr $>|\mathbf{t}|$ \\
\hline Intercept & 1.302 & & 0.023 & 55.89 & $<\mathbf{0 . 0 0 1}$ \\
Unemployment months & 0.014 & 0.052 & 0.004 & 3.23 & 0.001
\end{tabular}

\begin{tabular}{lccccr}
\multicolumn{1}{c}{ Multivariate Model } & b & $\boldsymbol{\beta}$ & $\begin{array}{c}\text { Standard } \\
\text { Error }\end{array}$ & t-Value & Pr $>|\mathbf{t}|$ \\
\hline Intercept & 17.940 & & 6.332 & 2.83 & 0.005 \\
Unemployment months & 0.0112 & 0.039 & 0.004 & 2.58 & $\mathbf{0 . 0 1 0}$ \\
Self-report Physical Health in & 0.333 & 0.185 & 0.026 & 12.90 & $<\mathbf{0 . 0 0 1}$ \\
2000 & & & & & \\
CESD score in 2000 & 0.297 & 0.284 & 0.018 & 16.14 & $<.0001$ \\
Age in 2012 & -0.009 & -0.037 & 0.003 & -2.77 & $\mathbf{0 . 0 0 6}$ \\
Gender (Male) & 0.000 & & 0.000 & & \\
Female & 0.122 & 0.032 & 0.047 & 2.58 & $\mathbf{0 . 0 1 0}$ \\
Race (White/Caucasian) & 0.000 & & 0.000 & & \\
Black/African American & -0.183 & -0.026 & 0.071 & -2.58 & $\mathbf{0 . 0 1 0}$ \\
Other & -0.017 & 0.002 & 0.145 & 0.12 & 0.906 \\
Ethnicity (Non-Hispanic) & 0.000 & & 0.000 & & \\
Hispanic & 0.204 & 0.027 & 0.108 & 1.89 & 0.059 \\
Household Income & 0.000 & -0.007 & 0.000 & -0.76 & 0.446 \\
Education (Less than HS) & 0.000 & & 0.000 & & \\
GED or HS & -0.365 & -0.095 & 0.075 & -4.85 & $<\mathbf{0 . 0 0 1}$ \\
No Degree, Some College & -0.357 & -0.082 & 0.083 & -4.33 & $<\mathbf{0 . 0 0 1}$ \\
College Graduate and above & -0.530 & -0.126 & 0.081 & -6.56 & $<\mathbf{0 . 0 0 1}$
\end{tabular}




\begin{tabular}{lcccrr} 
& \multicolumn{6}{c}{ Estimated Regression Coefficients } \\
\multicolumn{1}{c}{ Univariate Model } & \multicolumn{3}{c}{$\begin{array}{c}\text { Standard } \\
\text { Error }\end{array}$} & t-Value & Pr > $|\mathbf{t}|$ \\
\hline Marital Status (Married) & 0.000 & & 0.000 & & \\
Partnered & -0.209 & -0.017 & 0.101 & -2.08 & $\mathbf{0 . 0 3 8}$ \\
Divorced & 0.235 & 0.040 & 0.086 & 2.73 & $\mathbf{0 . 0 0 6}$ \\
Widowed & 0.363 & 0.086 & 0.060 & 6.09 & $<\mathbf{0 . 0 0 1}$ \\
Never Married & 0.325 & 0.038 & 0.137 & 2.38 & $\mathbf{0 . 0 1 7}$ \\
Census Region (East) & 0.000 & & 0.000 & & \\
Midwest & -0.218 & -0.052 & 0.699 & -3.12 & $\mathbf{0 . 0 0 2}$ \\
South & -0.158 & -0.042 & 0.067 & -2.37 & $\mathbf{0 . 0 1 8}$ \\
West & -0.103 & -0.014 & 0.079 & -1.31 & 0.192
\end{tabular}

\section{Discussion}

Prior research has indicated that when job loss resulted in early retirement, mental health declined, although workforce re-entry has been related to restoration of prior levels of mental health (Mandal \& Roe, 2008). Unemployment in the pre-retirement years has a lasting negative effect on mental health and satisfaction with life (Voss et al., 2017). Unemployment has been consistently and reliably linked to negative psychological states and impaired mental health (Paul \& Moser, 2009) and other evidence shows that these effects do not dissipate among older adults even when there is a return to work (Gallo et al., 2006). The findings presented here add support to this prior research. In this analysis of the HRS there was a direct negative effect of late-career unemployment on mental health (CES-D scores) in retirement. Additionally, late-career unemployment was associated with higher levels of involuntary retirement timing, which has also been linked to negative health effects in prior research (Dave et al., 2008; Rhee et al., 2016; Van Solinge, 2007). 
The finding that levels of late-career unemployment had a long-term negative impact on mental health are important, particularly as the population ages. Combined with evidence that a return to work improves well-being among those who were forced into retirement (Dingemans \& Henkens, 2014; Mandal \& Roe, 2008), it suggests the importance of providing support to older workers who would like to extend their working careers. Yet the evidence that forced, delayed retirement results in physical health declines also indicates the importance of choice in the health and wellbeing consequences of working at older ages (Shai, 2017). Choice in working during retirement was identified as a key component to well-being in interviews with retirees who faced late-career job loss (redacted for blind review, in press). There has been a trend toward bridge employment, as older adults choose second careers or alternative work arrangements after a partial retirement from their earlier work life (Zhan et al., 2009). Future research should address the role of bridge employment in the context of unemployment and involuntary retirement to understand the full impact of occupational factors on retirement health outcomes.

The results of this study demonstrated no significant effect of late-career unemployment on the physical health of retirees, whether examining results from self-reported physical health status or more objective measures of nights in hospital and doctor diagnosed chronic conditions. Similarly, when controlling for the effects of involuntary retirement status, unemployment still had no relationship with changes in self-reported physical health status. One important limitation in this study is the use of survey questions contained in the HRS which may not effectively delineate unemployment from retirement. Our prior work interviewing with retirees experiencing late-career job loss suggests potential error in the measurement of unemployment that occurs at retirement age, underestimating unemployment status by as much as $17 \%$ (redacted for blind review, in press). In this previous research, interviewees were likely to report voluntary 
retirement as their status via survey, despite reporting in an interview that a job loss scenario prompted their retirement timing. In these cases, a single question about labor force status in a survey would not record unemployment as the labor force status and it is uncertain whether these individuals would record their retirement timing as voluntary or forced. This error in measurement potentially skews any investigation into the effects of late-career unemployment on retirement health. If the HRS data are comparable, and as much as $17 \%$ of the respondents with job loss never record their status as unemployed, the data analysis in this study could be biased due to measurement error. Future surveys must address this distinction between late-career unemployment and early or forced retirement to correctly identify when job loss has prompted retirement before a more accurate assessment of the long-term health effects of late-career job loss can be conducted. Given the noted association between involuntary retirement and unemployment experiences, as well as changes to retirement age, the investigators have intentions for future investigations creating an index score that better assesses late-career job instability to better assess its health effects.

This study is quite limited in its focus on the relationship between job loss and involuntary retirement on retirement health. The role of known health covariates such as prior health, gender, race/ethnicity, education, and marital status were incorporated into the analysis, but no mediational analysis was completed. An additional limitation of this research is that it did not comprehensively examine the characteristics of the work environment prior to job loss or retirement and did not comprehensively examine the role of bridge employment or part-time work during retirement. Whether or not retirement is experienced as a positive and liberating experience versus a time of loss of control and declining well-being is dependent on a wide array of work and activity conditions (Drentea, 2002). Employment during the retirement years is 
associated with increased social networks (Mor-Barak, Scharlach, Birba, \& Sokolov, 1992) suggesting the importance of evaluating social variables as well as activity variables in retirement health (Glass, De Leon, Bassuk, \& Berkman, 2006). Additional analysis is planned with comprehensive data-mining to determine the role of the multiple employment, social, and activity variables in the relationships between employment, retirement, and health. Data-mining uses machine learning algorithms to identify the top predictive features and is an a-theoretical approach. In this way, potential relationships between variables that are not intuitive can be identified and explored. Given the complexity of factors related to the retirement context, this approach may help to further unravel the complex relationships between occupational factors and retirement health.

The current analysis and length of the study follow-up was limited in its design, focusing on the long-lasting impact of unemployment on health in retirement. The study included only individuals reported as actively in the labor force in the study wave in 2000 and retired by 2012, rather than the full array of bridge and partial work arrangements possible to older adults. This design captured all reports of unemployment during that period, but there were varying lengths of retirement which may have reduced the ability to identify health effects. Future research is planned which will examine physical and mental health at 2 years, 5 years, and 10 years post retirement.

Prior research has found post-retirement physical and mental health is more likely to decline among individuals who experience involuntary or early retirement (Calvo, Sarkisian, \& Tamborini, 2013; Rhee et al., 2016). While our research showed higher rates of involuntary retirement among those experiencing late-career job loss, there was no effect of late-career unemployment on self-reported physical health outcomes, even though mental health declined in 
this group. Past research has identified an earlier retirement age among those with late-career job loss (Johnson \& Butrica, 2012; Voss et al., 2017), however, the current study identified an older retirement age, consistent with Government Accountability Office projections that an episode of late-career unemployment drains retirement savings and requires additional work years to recoup lost retirement income (Government.Accountability.Office, 2012).

\section{Implications}

Returning to work after an episode of late-career unemployment has a number of natural barriers related to the monetization of time and slowing life pace of older workers. Full-time work may place unreasonable demands on aging workers and add barriers to re-employment (Van Horn et al., 2011). These barriers are most likely to be problematic when economic cycles are not favorable to the worker (Coile \& Levine, 2011; Van Horn et al., 2011). Evidence was presented that older unemployed workers may have difficulty finding new employment that matches their prior income, in addition to facing the traditional job-search challenges such as updating skills for a changing job market (Chan \& Stevens, 2004; Hetschko et al., 2014). The findings of this research demonstrate a negative long-term effect on mental health for individuals experiencing late-career job loss. Public health and occupational medicine organizations should lead out in providing practical policy provisions that make it easier for older workers to remain in the labor force or find re-employment and skills re-training as needed. Changes in social and industry policy regarding full versus partial retirement might help ease the labor burdens placed on aging workers and shift the incentives to remaining in the labor force. Future research should consider the relationship of late-career job loss to bridge and part-time employment as potential mediators of the negative mental health effect identified here among those with late-career unemployment. 


\section{Data Access Statement:}

This study utilized data publicly available upon request and subject to license restrictions from the Health and Retirement Study and the RAND Corporation. Full details on data and available documentation can be accessed at https://hrs.isr.umich.edu/about?_ga=2.215381264.687458793.1521561157-

1046551118.1521039304. Additional details about analysis and models may be obtained by contacting the corresponding author. 


\section{References}

Aging, A. (2017). A profile of older Americans: 2016. Washington, D.C.

Beehr, T. A. (1986). The process of retirement: A review and recommendations for future investigation. Personnel Psychology, 39(1), 31-55.

Behncke, S. (2012). Does retirement trigger ill health? Health Economics, 21(3), 282-300. doi: $10.1002 /$ hec. 1712

Bloemen, H., Hochguertel, S., \& Zweerink, J. (2017). The causal effect of retirement on mortality: Evidence from targeted incentives to retire early. Health Economics, 26(12), e204-e218. doi:10.1002/hec.3493

Bockerman, P., \& Ilmakunnas, P. (2009). Unemployment and self-assessed health: evidence from panel data. Health Economics, 18(2), 161-179. doi:10.1002/hec.1361

Browning, M., \& Heinesen, E. (2012). Effect of job loss due to plant closure on mortality and hospitalization. Journal of Health Economics, 31(4), 599-616.

Browning, M., Moller Dano, A., \& Heinesen, E. (2006). Job displacement and stress-related health outcomes. Health Economics, 15(10), 1061-1075.

Burgard, S. A., Ailshire, J. A., \& Kalousova, L. (2013). The Great Recession and Health People, Populations, and Disparities. The ANNALS of the American Academy of Political and Social Science, 650(1), 194-213.

Calvo, E., Haverstick, K., \& Sass, S. A. (2009). Gradual retirement, sense of control, and retirees' happiness. Research on Aging, 31(1), 112-135. 
Calvo, E., Sarkisian, N., \& Tamborini, C. R. (2013). Causal effects of retirement timing on subjective physical and emotional health. The Journals of Gerontology Series B: Psychological Sciences and Social Sciences, 68(1), 73-84.

Chan, S., \& Stevens, A. H. (2004). How does job loss affect the timing of retirement? Contributions in Economic Analysis \& Policy, 3(1).

Cheak-Zamora, N. C., Wyrwich, K. W., \& McBride, T. D. (2009). Reliability and validity of the SF-12v2 in the medical expenditure panel survey. Quality of Life Research, 18(6), 727735.

Chen, J., Rizzo, J. A., \& Rodriguez, H. P. (2011). The health effects of cost-related treatment delays. American Journal of Medical Quality, 26(4), 261-271.

Chien, S., Campbell, N., Chan, C., Hayden, O., Hurd, M., Main, R., . . Meijer, E. (2015). RAND HRS Data Documentation, Version O. RAND Center for the Study of Aging: Santa Monica, CA, USA.

Coe, N. B., \& Zamarro, G. (2011). Retirement effects on health in Europe. Journal of Health Economics, 30(1), 77-86.

Coile, C. C., \& Levine, P. B. (2011). The market crash and mass layoffs: How the current economic crisis may affect retirement. The BE Journal of Economic Analysis \& Policy, 11(1). doi:doi.org/10.2202/1935-1682.2568

Coile, C. C., Levine, P. B., \& McKnight, R. (2014). Recessions, older workers, and longevity: How long are recessions good for your health? American Economic Journal: Economic Policy, 6(3), 92-119.

Dave, D., Rashad, I., \& Spasojevic, J. (2008). The effects of retirement on physical and mental health outcomes. Southern Economic Journal, 75, 497-523. 
Dingemans, E., \& Henkens, K. (2014). Involuntary retirement, bridge employment, and satisfaction with life: A longitudinal investigation. Journal of Organizational Behavior, $35(4), 575-591$.

Dooley, D., Fielding, J., \& Levi, L. (1996). Health and unemployment. Annual Review of Public Health, 17(1), 449-465.

Drentea, P. (2002). Retirement and mental health. Journal of Aging and Health, 14(2), 167-194.

Eibich, P. (2015). Understanding the effect of retirement on health: Mechanisms and heterogeneity. Journal of Health Economics, 43, 1-12.

doi:10.1016/j.jhealeco.2015.05.001

Ekerdt, D. J., Bosse, R., \& LoCastro, J. S. (1983). Claims that retirement improves health. Journal of Gerontology, 38(2), 231-236.

Fisher, E. S., Wennberg, D. E., Stukel, T. A., Gottlieb, D. J., Lucas, F. L., \& Pinder, E. L. (2003). The implications of regional variations in Medicare spending. Part 1: the content, quality, and accessibility of care. Annals of Internal Medicine, 138(4), 273-287.

Fisher, G. G., Chaffee, D. S., \& Sonnega, A. (2016). Retirement timing: A review and recommendations for future research. Work, Aging and Retirement, 2(2), 230-261.

Flint, E., Bartley, M., Shelton, N., \& Sacker, A. (2013). Do labour market status transitions predict changes in psychological well-being? Journal of Epidemiology and Community Health, 67(9), 796-802.

Fryer, D. (1986). Employment deprivation and personal agency during unemployment: A critical discussion of Jahoda's explanation of the psychological effects of unemployment. Social Behavior, 1, 3-23. 
Furunes, T., Mykletun, R. J., Solem, P. E., de Lange, A. H., Syse, A., Schaufeli, W. B., \& Ilmarinen, J. (2015). Late career decision-making: A qualitative panel study. Work, Aging and Retirement, 1(3), 284-295.

Gallo, W. T., Bradley, E. H., Dubin, J. A., Jones, R. N., Falba, T. A., Teng, H. M., \& Kasl, S. V. (2006). The persistence of depressive symptoms in older workers who experience involuntary job loss: results from the health and retirement survey. The Journals of Gerontology Series B: Psychological Sciences and Social Sciences, 61(4), S221-228.

Gerstorf, D., Ram, N., Röcke, C., Lindenberger, U., \& Smith, J. (2008). Decline in Life Satisfaction in Old Age: Longitudinal Evidence for Links to Distance from Death. Psychology and Aging, 23(1), 154-168. doi:10.1037/0882-7974.23.1.154

Glass, T. A., De Leon, C. F., Bassuk, S. S., \& Berkman, L. F. (2006). Social engagement and depressive symptoms in late life: longitudinal findings. Journal of Aging and Health, 18(4), 604-628. doi:10.1177/0898264306291017

Gonzalez, P., Nunez, A., Merz, E., Brintz, C., Weitzman, O., Navas, E. L., . . Gallo, L. C. (2017). Measurement properties of the Center for Epidemiologic Studies Depression Scale (CES-D 10): Findings from HCHS/SOL. Psychological Assessment, 29(4), 372381. doi:10.1037/pas0000330

Government.Accountability.Office. (2012). Unemployed older workers: Many experience challenges regaining employment and face reduced retirement security. Retrieved from Washington, D.C.:

Granados, J. A. T., House, J. S., Ionides, E. L., Burgard, S., \& Schoeni, R. S. (2014). Individual joblessness, contextual unemployment, and mortality risk. American Journal of Epidemiology, 180(3), 280-287. 
Hetschko, C., Knabe, A., \& Schöb, R. (2014). Changing identity: Retiring from unemployment. The Economic Journal, 124(575), 149-166.

Hughes, A., Kumari, M., McMunn, A., \& Bartley, M. (2017). Unemployment and inflammatory markers in England, Wales and Scotland, 1998-2012: Meta-analysis of results from 12 studies. Brain Behav Immun, 64, 91-102. doi:10.1016/j.bbi.2017.03.012

Jahoda, M. (1982). Employment and unemployment: A social-psychological analysis (Vol. 1): Cambridge University Press.

Jin, R. L., Shah, C. P., \& Svoboda, T. J. (1995). The impact of unemployment on health: a review of the evidence. CMAJ: Canadian Medical Association Journal, 153(5), 529-540.

Johnson, R. W., \& Butrica, B. A. (2012). Age disparities in unemployment and reemployment during the Great Recession and recovery. Unemployment and Recovery Project Brief, 3.

Jokela, M., Ferrie, J. E., Gimeno, D., Chandola, T., Shipley, M. J., Head, J., . . Kivimaki, M. (2010). From midlife to early old age: Health trajectories associated with retirement. Epidemiology, 21(3), 284-290. doi:10.1097/EDE.0b013e3181d61f53

Kachan, D., Fleming, L. E., Christ, S., Muennig, P., Prado, G., Tannenbaum, S. L., . . Lee, D. J. (2015). Health Status of Older US Workers and Nonworkers, National Health Interview Survey, 1997-2011. Preventing Chronic Disease, 12, E162. doi:10.5888/pcd12.150040

Kremer, Y. (1985). The association between health and retirement: self-health assessment of Israeli retirees. Social Science and Medicine, 20(1), 61-66.

Leist, A. K., Hessel, P., \& Avendano, M. (2014). Do economic recessions during early and midadulthood influence cognitive function in older age? J Epidemiol Community Health, 68(2), 151-158. doi:10.1136/jech-2013-202843 
Levanon, G., \& Cheng, B. (2011). US workers delaying retirement: Who and why and implications for businesses. Business Economics, 46(4), 195-213.

Mandal, B., \& Roe, B. (2008). Job loss, retirement and the mental health of older Americans. Journal of Mental Health Policy and Economics, 11(4), 167-176.

Moon, J. R., Glymour, M. M., Subramanian, S. V., Avendano, M., \& Kawachi, I. (2012). Transition to retirement and risk of cardiovascular disease: Prospective analysis of the US health and retirement study. Social Science and Medicine, 75(3), 526-530. doi:10.1016/j.socscimed.2012.04.004

Mor-Barak, M. E., Scharlach, A. E., Birba, L., \& Sokolov, J. (1992). Employment, social networks, and health in the retirement years. International Journal of Aging and Human Development, 35(2), 145-159. doi:10.2190/tvev-fu7e-ne33-tkyc

Norman, G. (2010). Likert scales, levels of measurement and the "laws" of statistics. Advances in health sciences education, 15(5), 625-632.

Paul, K. I., \& Moser, K. (2009). Unemployment impairs mental health: Meta-analyses. Journal of Vocational Behavior, 74(3), 264-282.

Peitsch, L., Tyas, S. L., Menec, V. H., \& St John, P. D. (2016). General life satisfaction predicts dementia in community living older adults: a prospective cohort study. International Psychogeriatrics, 1-9. doi:10.1017/s1041610215002422

Quinn, J. (2010). Work, retirement, and the encore career: Elders and the future of the American workforce. Generations, 34(3), 45-55.

Radloff, L. S. (1977). The CES-D scale a self-report depression scale for research in the general population. Applied Psychological Measurement, 1(3), 385-401. 
RAND. (2000-2012). Health and Retirement Study public use dataset. Produced and distributed by the University of Michigan with funding from the National Institute on Aging (grant number NIA U01AG009740). Ann Arbor, MI.

Rhee, M. K., Mor Barak, M. E., \& Gallo, W. T. (2016). Mechanisms of the Effect of Involuntary Retirement on Older Adults' Self-Rated Health and Mental Health. Journal of Gerontological Social Work, 59(1), 35-55. doi:10.1080/01634372.2015.1128504

Rosenthal, L., Carroll-Scott, A., Earnshaw, V. A., Santilli, A., \& Ickovics, J. R. (2012). The importance of full-time work for urban adults' mental and physical health. Social Science and Medicine, 75(9), 1692-1696.

Salm, M. (2009). Does unemployment cause ill health. Health Economics, 18(9), 1075-1089.

Salyers, M. P., Bosworth, H. B., Swanson, J. W., Lamb-Pagone, J., \& Osher, F. C. (2000). Reliability and validity of the SF-12 health survey among people with severe mental illness. Medical Care, 38(11), 1141-1150.

Schmitz, H. (2011). Why are the unemployed in worse health? The causal effect of unemployment on health. Labour Economics, 18(1), 71-78.

Shai, O. (2017). Is retirement good for men's health? Evidence using a change in the retirement age in Israel. Journal of Health Economics, 57, 15-30. doi:10.1016/j.jhealeco.2017.10.008

StataCorp, L. (2015). Stata version 14.0. College Station, TX: StataCorp LP.

Sullivan, D., \& Von Wachter, T. (2009). Job displacement and mortality: An analysis using administrative data. The Quarterly Journal of Economics, 124(3), 1265-1306. 
van der Heide, I., van Rijn, R. M., Robroek, S. J., Burdorf, A., \& Proper, K. I. (2013). Is retirement good for your health? A systematic review of longitudinal studies. BMC Public Health, 13, 1180. doi:10.1186/1471-2458-13-1180

Van Horn, C. E., Corre, N., \& Heidkamp, M. (2011). Older workers, the great recession, and the impact of long-term unemployment. Public Policy \& Aging Report, 21(1), 29-33.

Van Solinge, H. (2007). Health change in retirement a longitudinal study among older workers in the Netherlands. Research on Aging, 29(3), 225-256.

Varanka-Ruuska, T., Rautio, N., Lehtiniemi, H., Miettunen, J., Keinanen-Kiukaanniemi, S., Sebert, S., \& Ala-Mursula, L. (2017). The association of unemployment with glucose metabolism: a systematic review and meta-analysis. Int J Public Health. doi:10.1007/s00038-017-1040-z

Voss, M. W., Birmingham, W. C., Wadsworth, L., Chen, W., Bounsanga, J., Gu, Y., \& Hung, M. (2017). Honest Labor Bears a Lovely Face: Will Late-Life Unemployment Impact Health and Satisfaction in Retirement? Journal of Occupational and Environmental Medicine.

Wang, M., \& Shultz, K. S. (2010). Employee retirement: A review and recommendations for future investigation. Journal of Management, 36(1), 172-206.

Wu, C., Odden, M. C., Fisher, G. G., \& Stawski, R. S. (2016). Association of retirement age with mortality: a population-based longitudinal study among older adults in the USA. Journal of Epidemiology and Community Health, 70(9), 917-923.

Zhan, Y., Wang, M., Liu, S., \& Shultz, K. S. (2009). Bridge employment and retirees' health: a longitudinal investigation. Journal of Occupational Health Psychology, 14(4), 374-389. doi:10.1037/a0015285 
